NISSUNA UMANA INVESTIGAZIONE SI PUO DIMANDARE VERA SCIENZIA S'ESSA NON PASSA PER LE MATEMATICHE DIMOSTRAZIONI LEONARDO DA VINCI

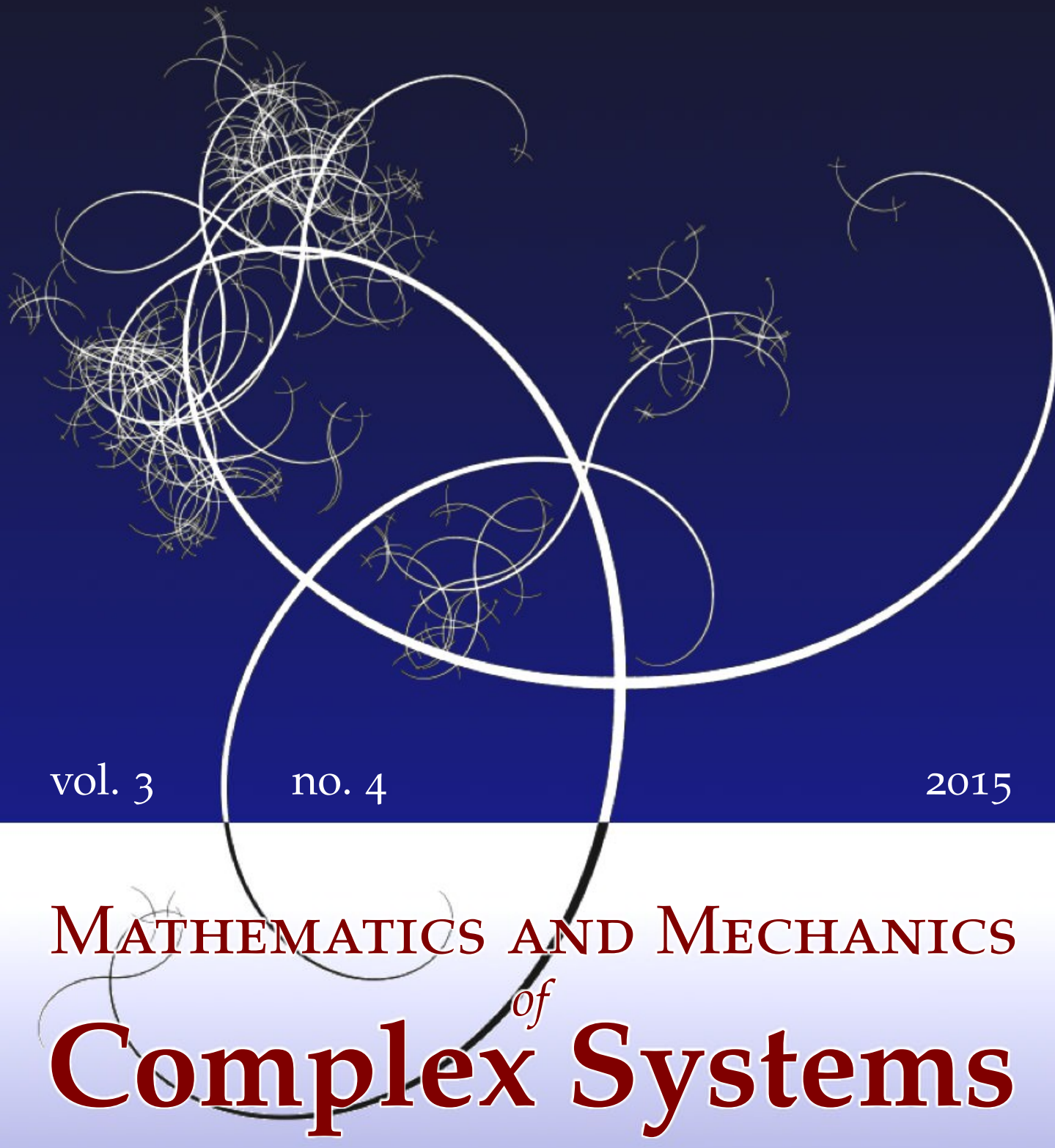

André Preumont, Matteo Voltan, Andrea Sangiovanni, RENAUd BASTAits, Bilal MOKRani AND DaVid Alaluf

AN INVESTIGATION OF THE ACTIVE DAMPING OF SUSPENSION BRIDGES 


\title{
AN INVESTIGATION OF THE ACTIVE DAMPING OF SUSPENSION BRIDGES
}

\author{
André Preumont, Matteo Voltan, Andrea Sangiovanni, \\ RENAUd BASTAITS, BILAL MOKRANi AND DAVID ALALUF
}

\begin{abstract}
This paper explores the feasibility of active damping of suspension bridges with the addition of stay cables controlled by active tendons. An active tendon consists of a displacement actuator collocated with a force sensor monitoring the tension in the cable. The active tendons are controlled by decentralized integral force feedback (IFF). In the first part of the paper, the potential of the control strategy is evaluated on a numerical model of an existing footbridge; several configurations are investigated where the active cables connect the pylon to the deck or the deck to the catenary. The analysis confirms that it is possible to provide a set of targeted modes with a considerable amount of damping, reaching $\xi=15 \%$. In the second part of the paper, the control strategy is demonstrated experimentally on a laboratory mock-up equipped with four control stay cables equipped with piezoelectric actuators. The experimental results confirm the excellent performance and robustness of the control system and the very good agreement with the predictions.
\end{abstract}

\section{Introduction}

Suspension bridges and cable-stayed bridges are widely used in infrastructures because they are elegant and allow very long spans. However, they are subjected to all sorts of complicated dynamic phenomena ranging from wind- or trafficinduced vibration to flutter instability (e.g., the Tacoma Narrows Bridge). The problem is difficult, in particular because of the highly nonlinear behavior of cable structures, responsible for such phenomena as parametric excitation when some tuning conditions are satisfied [Nayfeh and Mook 1979; Pinto da Costa et al. 1996; Lilien and Pinto da Costa 1994]. Footbridges are very sensitive to pedestrianand jogger-induced vibrations. It is generally admitted that the over-sensitivity to dynamic excitation of cable bridges is associated with the very low structural damping in the global bridge modes (often below $1 \%$ and even less in the cable

\section{Communicated by Antonio Carcaterra.}

MSC2010: primary 70Q05, 70J25, 74H45; secondary 93C95.

Keywords: vibrations, damping, control, active structure, bridge, mechatronics, piezoelectric. 
modes [Pacheco et al. 1993]). The classical way of attenuating the global modes is the use of tuned mass dampers (at least one by critical mode) [Caetano et al. 2010; Tubino and Piccardo 2015]. The active control of cable structures has also been considered; the application of active tendons to flutter control was considered numerically in [Yang and Giannopoulos 1979a; 1979b] and experimental studies were pioneered in [Warnitchai et al. 1993; Fujino and Susumpow 1994; Fujino et al. 1993]. All these studies were performed with noncollocated actuator-sensor configurations; this did not lead to any trouble in Yang's numerical study since perfect knowledge and a linear system were assumed, but Fujino's experimental results revealed that, even for relatively simple systems, instabilities tend to occur when the cable-structure interaction is large.

It turns out that cable-structure systems are much easier to control if collocated actuator-sensor pairs are used because this produces alternating poles and zeros in the open-loop transfer function of every channel of the control system [Cannon and Rosenthal 1984; Preumont 2011], drastically reducing the spillover and other problems associated with the high-frequency dynamics. This property was successfully exploited in several studies demonstrating the active damping of cablestayed bridges [Achkire and Preumont 1996; Achkire et al. 1998; Bossens and Preumont 2001] and guyed space trusses [Preumont and Bossens 2000; Preumont and Achkire 1997; Preumont et al. 2000]. All these studies use a decentralized control strategy based on the integral force feedback (IFF) family [Preumont et al. 1992]. The control strategy exhibits very good performance and robustness, and the control design is based on clear physical parameters such as natural frequencies and modal strain energy; the method is summarized in Appendix A.

At the end of the 1990s, the European Union research program Brite-Euram funded a large-scale demonstration project named "ACE", conducted by a consortium involving several academic and industrial partners; this project confirmed the results obtained on smaller test beds [Bossens and Preumont 2001]. However, the selected application of the cable-stayed bridge had a significant drawback: the stay cables had to carry the control loads but also the dead loads, which were substantially larger than the control loads and complicated significantly the design of the active tendons. This is probably why the idea did not go further towards applications.

At the end of the ACE project, our partner from Bouygues, M. Auperin [Auperin and Dumoulin 2001], suggested that active damping of suspension bridges could be achieved with a very small number of stay cables equipped with active tendons (Figure 1) without the drawback just described for the cable-stayed bridges of having to carry a substantial part of the dead loads. This idea received little attention at the time and was not pursued for lack of funding. The curiosity of exploring Dr. Auperin's idea (15 years later!) is the motivation of the present study. 


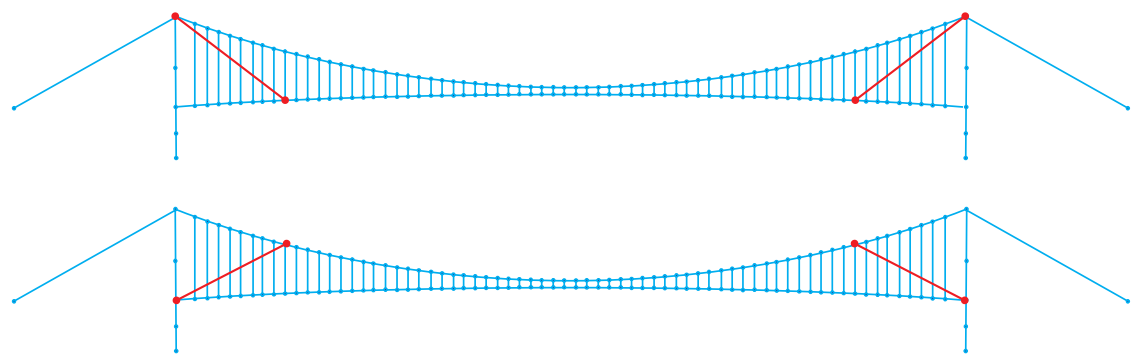

Figure 1. Various configurations for active tendon control of suspension bridges (the active control cables are in red).

\section{Seriate footbridge}

Model. A model of the Seriate footbridge (Figure 2) was used to evaluate the active control strategy. The footbridge, located in Northern Italy near the city of Bergamo, has been reported to exhibit excessive vibrations induced by the passage of pedestrians. The survey carried out by Professor C. Gentile (personal communication, 2014) revealed that the passage of eight walking pedestrians induces a vertical acceleration of $1.8 \mathrm{~m} / \mathrm{s}^{2}$ and the vertical acceleration induced by four joggers reaches $4 \mathrm{~m} / \mathrm{s}^{2}$. These values are far beyond those recommended by the European HiVoSS guidelines [Van Nimmen et al. 2014]. The third and fourth bending modes, respectively at $2.17 \mathrm{~Hz}$ (modal damping $\xi_{3}=1.48 \%$ ) and $2.86 \mathrm{~Hz}$ $\left(\xi_{4}=1.5 \%\right)$, were identified as the critical modes within the pedestrian excitation range $^{1}$ and will be the target of the active control system.



Figure 2. View of the Seriate footbridge.

${ }^{1}$ The typical pedestrian excitation range for walking is $1.6-2.4 \mathrm{~Hz}$, for running is $2.0-3.5 \mathrm{~Hz}$, and for jumping is $1.8-3.4 \mathrm{~Hz}$. 




Figure 3. 3D model of the Seriate footbridge, with in red a possible configuration of 4 active stay cables.

The bridge has a span of $64 \mathrm{~m}$, the deck weighs $40 \mathrm{~T}$, the main steel cables (catenary) have a diameter of $60 \mathrm{~mm}$, and the $2 \times 21$ hangers have a diameter of $16 \mathrm{~mm}$ and a mean tension force of $15.3 \mathrm{kN}$ according to the data sheet. The columns are articulated at the base and connected at the top; the main cables holding the column have an axial load of $425 \mathrm{kN}$ according to the data sheet. In the SAMCEF model (Figure 3), the deck is modeled with finite elements of beams with bending

\begin{tabular}{|c|c|c|c|c|c|}
\hline Mode & $\begin{array}{c}\text { 2D numer. } \\
(\mathrm{Hz})\end{array}$ & $\begin{array}{c}\text { 3D numer. } \\
(\mathrm{Hz})\end{array}$ & $\begin{array}{l}\text { Exper. } \\
(\mathrm{Hz})\end{array}$ & $\begin{array}{c}\text { Numer. } \\
\text { mode shape }\end{array}$ & $\begin{array}{c}\text { Exper. } \\
\text { mode shape }\end{array}$ \\
\hline 1B & 1.03 & 1.02 & $\begin{array}{c}1.03 \\
=2.77 \%\end{array}$ & & \\
\hline $2 B$ & 1.39 & 1.48 & $\begin{array}{c}1.48 \\
=1.34 \%\end{array}$ & & \\
\hline $1 \mathrm{~T}$ & & 1.79 & 1.92 & & \\
\hline $2 \mathrm{~T}$ & & 2.1 & 1.94 & & \\
\hline 3B & 2.22 & 2.20 & $\begin{array}{c}\mathbf{2 . 1 7} \\
=1.48 \%\end{array}$ & & \\
\hline $3 \mathrm{~T}$ & & 2.65 & 2.75 & & \\
\hline $4 B$ & 2.81 & 2.78 & $\begin{array}{c}\mathbf{2 . 8 6} \\
=1.50 \%\end{array}$ & & \\
\hline
\end{tabular}

Table 1. Natural frequencies and mode shapes of the Seriate footbridge, comparison of the 3D model and 2D model with experiments (personal communication, Gentile, 2014). The two critical modes are $3 \mathrm{~B}$ and $4 \mathrm{~B}$. 



Figure 4. Active control configurations of the Seriate footbridge. Top: active cable attached to the pylon. Bottom: active control attached to the catenary.

stiffness and mass matching those of the deck, the main cables are modeled with bars (one element between two hangers) following a parabola (approximation of the catenary), and the hangers are also modeled with bars (a single element per hanger). The initial shape is taken from the bridge geometry (with some minor simplifications such as the columns have been assumed of equal length), and the prestress in the hangers is achieved by applying a thermal field until the appropriate value is reached. This model was able to capture quite well the natural frequencies and the mode shapes measured on the actual bridge (personal communication, Gentile, 2014). A simplified 2D model was also developed, which was also well representative of the bending behavior of the bridge (Table 1).

Active damping. In this study, we will restrict ourselves to an active control configuration involving four symmetrically located active steel cables with a diameter of $10 \mathrm{~mm}$; the control system will consist of four independent identical loops with the same gain $g$. We first consider the situation where the active cables are attached to the pylons; the position of the attachment points with the deck is taken as a parameter, restricting us to the positions where the hangers are attached (Figure 4, top).

According to the theory (see Appendix A), the closed-loop poles follow closely the root locus

$$
1+g \frac{s^{2}+\omega_{i}^{2}}{s\left(s^{2}+\Omega_{i}^{2}\right)}=0,
$$

where the frequency $\omega_{i}$ is the natural frequency when all the active cables are removed and $\Omega_{i}$ is the natural frequency when the four active cables are included. The maximum damping ratio that can be achieved on one mode is given by

$$
\xi_{i}^{\max }=\frac{\Omega_{i}-\omega_{i}}{2 \omega_{i}} .
$$




\begin{tabular}{|ccccccccccc|}
\hline & \multicolumn{1}{c}{ Position A } & \multicolumn{3}{c|}{ Position B } & \multicolumn{3}{c|}{ Position C } & \multicolumn{2}{c|}{ Position D } \\
Mode & $\omega_{i}$ & $\Omega_{i}$ & $\xi_{i}^{\max }$ & $\Omega_{i}$ & $\xi_{i}^{\max }$ & $\Omega_{i}$ & $\xi_{i}^{\max }$ & \multicolumn{2}{c}{$\Omega_{i}$} & $\xi_{i}^{\max }$ \\
& $(\mathrm{Hz})$ & $(\mathrm{Hz})$ & $(\%)$ & $(\mathrm{Hz})$ & $(\%)$ & $(\mathrm{Hz})$ & $(\%)$ & $(\mathrm{Hz})$ & $(\%)$ \\
\hline 1B & 1.02 & 1.07 & 2.2 & 1.22 & 9.8 & 1.38 & 17.5 & 1.53 & 24.7 \\
2B & 1.48 & 1.49 & 0.6 & 1.54 & 2.1 & 1.55 & 2.5 & 1.53 & 1.8 \\
1T & 1.79 & 1.81 & 0.6 & 1.91 & 3.3 & 2.04 & 6.9 & 2.12 & 9.0 \\
2T & 2.10 & 2.10 & 0.2 & 2.13 & 1.5 & 2.13 & 0.8 & 2.18 & 2.0 \\
3B & 2.20 & 2.23 & $\mathbf{0 . 7}$ & 2.36 & $\mathbf{3 . 6}$ & 2.54 & $\underline{\mathbf{7 . 7}}$ & 2.64 & $\underline{\mathbf{1 0 . 0}}$ \\
3T & 2.65 & 2.65 & 0.0 & 2.65 & 0.0 & 2.65 & 0.0 & 2.65 & 0.0 \\
4B & 2.78 & 2.85 & $\mathbf{1 . 2 6}$ & 3.13 & $\mathbf{6 . 3}$ & 3.31 & $\underline{\mathbf{9 . 6}}$ & 3.17 & $\underline{\mathbf{7 . 1}}$ \\
4T & 3.26 & 3.28 & 1.7 & 3.37 & 1.7 & 3.52 & 3.9 & 3.66 & 6.1 \\
\hline
\end{tabular}

Table 2. Active control cables attached to the pylon. Natural frequencies with $\left(\Omega_{i}\right)$ and without $\left(\omega_{i}\right)$ active cables and maximum achievable (active) damping ratios $\xi_{i}$ for the various modes and the various positions of the active cables shown in Figure 4, top. The critical modes are in bold.

Table 2 shows the values that can be achieved for the various positions of the active cables investigated. Positions $\mathrm{C}$ and $\mathrm{D}$ are clearly very good positions for the targeted modes (3rd and 4th bending modes), with damping ratios between $7 \%$ and $10 \%$. Note that this is achieved with active cables with a diameter of $10 \mathrm{~mm}$ only.

Next, we consider the situation where the active cables connect the deck at the foot of the pylon to the catenary (Figure 4, bottom). Table 3 shows the key numbers

\begin{tabular}{|ccccccccccr|}
\hline & \multicolumn{1}{c}{ Position A } & \multicolumn{2}{c|}{ Position B } & \multicolumn{2}{c|}{ Position C } & \multicolumn{2}{c|}{ Position D } \\
Mode & $\omega_{i}$ & $\Omega_{i}$ & $\xi_{i}^{\max }$ & $\Omega_{i}$ & $\xi_{i}^{\max }$ & $\Omega_{i}$ & $\xi_{i}^{\max }$ & $\Omega_{i}$ & $\xi_{i}^{\max }$ \\
& $(\mathrm{Hz})$ & $(\mathrm{Hz})$ & $(\%)$ & $(\mathrm{Hz})$ & $(\%)$ & $(\mathrm{Hz})$ & $(\%)$ & $(\mathrm{Hz})$ & $(\%)$ \\
\hline 1B & 1.02 & 1.06 & 1.6 & 1.21 & 9.4 & 1.40 & 18.5 & 1.58 & 27.2 \\
2B & 1.48 & 1.50 & 0.6 & 1.56 & 2.9 & 1.59 & 4 & 1.58 & 3.4 \\
1T & 1.79 & 1.81 & 0.5 & 1.93 & 3.7 & 2.12 & 9.1 & 2.36 & 15.7 \\
2T & 2.10 & 2.11 & 0.3 & 2.16 & 1.5 & 2.18 & 1.9 & 2.16 & 1.5 \\
3B & 2.20 & 2.21 & $\mathbf{0 . 3}$ & 2.30 & $\mathbf{2 . 4}$ & 2.42 & $\underline{\mathbf{5 . 1}}$ & 2.90 & $\underline{\mathbf{1 5 . 9}}$ \\
3T & 2.65 & 2.65 & 0.0 & 2.66 & 0.0 & 2.66 & 0.1 & 2.66 & 0.1 \\
4B & 2.78 & 2.83 & $\mathbf{0 . 9}$ & 3.09 & $\mathbf{5 . 7}$ & 3.63 & $\underline{\mathbf{1 5 . 4}}$ & 3.59 & $\underline{\mathbf{1 4 . 7}}$ \\
4T & 3.26 & 3.27 & 0.1 & 3.35 & 1.3 & 3.54 & 4.3 & 3.81 & 8.3 \\
\hline
\end{tabular}

Table 3. Active control cables attached to the catenary. Natural frequencies with $\left(\Omega_{i}\right)$ and without $\left(\omega_{i}\right)$ active cables and maximum achievable damping ratio $\xi_{i}$ for the various modes and the various positions of the active cables shown in Figure 4, bottom. 
for the various positions corresponding to the attachment point of the hangers on the catenary. We note that, for position $\mathrm{D}$, the performances are even better than for the previous configuration, reaching $15 \%$ for both the $3 \mathrm{rd}$ and 4 th bending modes.

The performance of the control system expected on the basis of the previous discussion is excellent. However, although the approximate formula (2) has been verified experimentally on several occasions [Preumont 2011], one can always argue that the control system design is based on linear models that ignore all nonlinear aspects of cable structures and that robustness issues could eventually hamper the practical use of this technology. In order to investigate this, a laboratory mock-up has been built and tested.

\section{Laboratory mock-up}

The laboratory mock-up (Figure 5) consists of two articulated towers of $0.62 \mathrm{~m}$ at a distance of $2.2 \mathrm{~m}$; the deck is free to rotate at both ends and is attached to the catenary by two rows of 10 hangers. The catenary consists of a steel cable with a diameter of $1 \mathrm{~mm}$, and the hangers are made of steel cables of $0.5 \mathrm{~mm}$; the tension in the catenary and in the hangers can be adjusted with screws. The tension $T_{0}$ in a hanger is measured indirectly from its natural frequency $f$ according to the string formula

$$
f=\frac{1}{2 L} \sqrt{\frac{T_{0}}{\varrho A}},
$$

$f$ being measured by a noncontact custom-made laser sensor [Achkire and Preumont 1998]. In this way, it was possible to distribute the tension in the hangers uniformly. Two types of active cables have been tested, one steel cable similar to the hangers, with a diameter of $0.5 \mathrm{~mm}$, and one made of Dyneema with a diameter of $0.2 \mathrm{~mm}$;

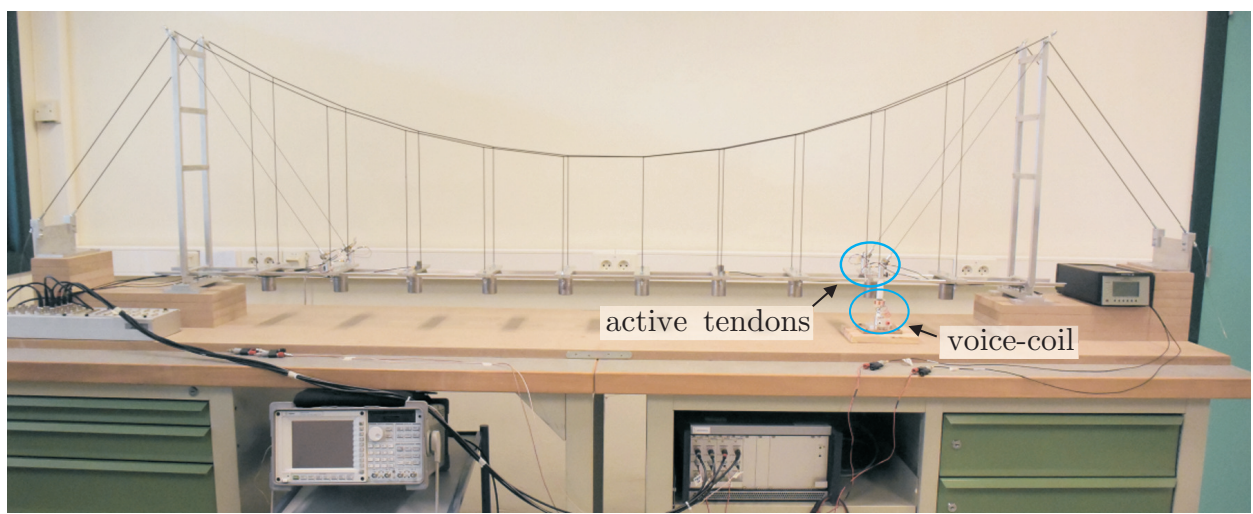

Figure 5. Laboratory mock-up equipped with four active cables connecting the pylon to the deck. 


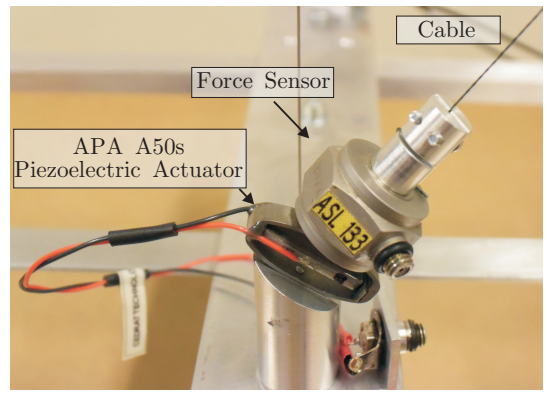

Figure 6. Detail of the active tendon.

only the results obtained with the steel cables are reported in this paper. The selected configuration uses active cables between the deck and the pylon (Figure 4, top) rather than the one with active cables attached to the catenary, which performs better, because it is closer to classical configurations in current $\mathrm{use}^{2}$ and therefore easier to accept by the bridge community. Figure 6 shows a close view of the active tendon; it consists of an APA-50s piezoelectric actuator from CEDRAT with a stroke of $52 \mu \mathrm{m}$ collocated with a B\&K 8200 force sensor connected with a Nexus charge amplifier (the charge amplifier acts as a second-order high-pass filter with a corner frequency adjustable between 0.1 and $1 \mathrm{~Hz}$ ). A small magnet is attached to the deck, and a voice coil is used to apply a disturbance to the structure (bandlimited white noise).

\begin{tabular}{|ccccc|}
\hline Mode & $\begin{array}{c}\text { Numer. } \\
(\mathrm{Hz})\end{array}$ & $\begin{array}{c}\text { Exper. } \\
(\mathrm{Hz})\end{array}$ & $\begin{array}{c}\text { Numer. } \\
\text { mode shape }\end{array}$ & $\begin{array}{c}\text { Exper. } \\
\text { mode shape }\end{array}$ \\
\hline 1B & 4.84 & 4.81 & \\
2B & 7.68 & 5.59 & \\
3B & 11.33 & 10.82 \\
4B & 17.93 & 18.25 \\
3T & 19.12 & 21.75 \\
5B & 28.01 & 28.84
\end{tabular}

Table 4. Laboratory demonstrator without control cables. Comparison between the numerical and experimental mode shapes and natural frequencies.

\footnotetext{
${ }^{2}$ e.g., the Albert Bridge (London, 1873) or Third Bosphorus Bridge (Turkey, under construction).
} 


\begin{tabular}{|ccccc|}
\hline Mode & $\begin{array}{c}\text { Numer. } \\
(\mathrm{Hz})\end{array}$ & $\begin{array}{c}\text { Exper. } \\
(\mathrm{Hz})\end{array}$ & $\begin{array}{c}\text { Numer. } \\
\text { mode shape }\end{array}$ & $\begin{array}{c}\text { Exper. } \\
\text { mode shape }\end{array}$ \\
\hline 1B & 7.7 & 6.0 & \\
2B & 12 & 12.1 & \\
3B & 21.1 & 20.2 & \\
4B & 29.3 & 28.8 & \\
\hline
\end{tabular}

Table 5. Laboratory demonstrator with four steel control cables of $0.5 \mathrm{~mm}$. Comparison between numerical and experimental mode shapes and natural frequencies.

Table 4 compares the experimental natural frequencies with the model predictions for the bridge without the active cables. The agreement is fairly good, except for the natural frequency of the second bending mode, which is overestimated by the model; the measured structural damping ratios range between $0.8 \%$ and $1 \%$.
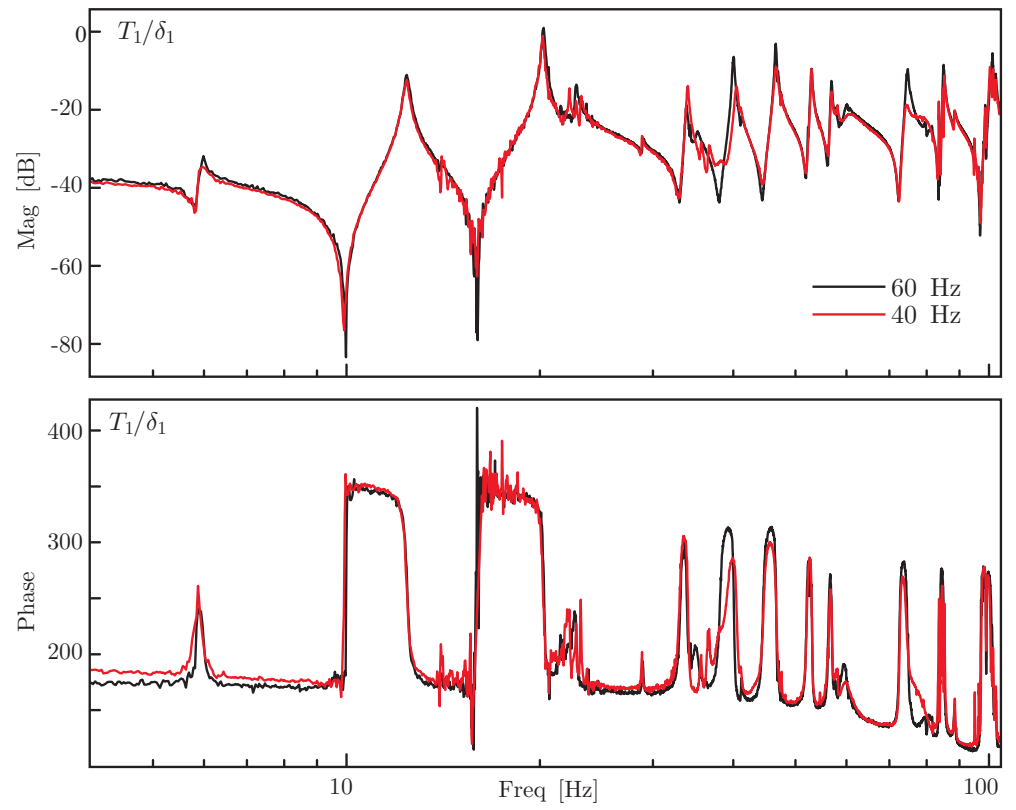

Figure 7. Experimental open-loop transfer functions $G(\omega)=T / \delta$ of one control loop for two values of the tension in the control cable corresponding to a natural frequency of the control cable of $40 \mathrm{~Hz}$ and $60 \mathrm{~Hz}$. 
Table 5 compares the experiments with the numerical predictions for the bridge with the active stay cables (without control). Some changes in the order of the modes are observed: the first bending mode has the shape of the second mode of the bridge without active cables, and the second mode has a shape similar to the first mode without active cables. Figure 7 shows the open-loop transfer functions $T / \delta$ of one of the four individual control loops (with the three other control cables passive) for two values of the tension in the control cable corresponding to a natural frequency of the control cable of $40 \mathrm{~Hz}$ and $60 \mathrm{~Hz}$; the curves exhibit alternating poles and zeros even above the natural frequency of the local mode of the control cable. According to (2), the distance between the poles $\Omega_{i}$ and the zeros $\omega_{i}$ is a measure of the controllability of the various modes (with a single loop). The very good agreement between the curves for the four loops (not shown) is representative of the good symmetry of the experimental set-up [Sangiovanni and Voltan 2015].

\section{Active damping with one loop}

The control law is the integral force feedback (IFF) $H(s)=g / s$, with minor modification at low frequency because of the charge amplifier. The loop gain $G H(\omega)$ is shown in Figure 8 (the pure IFF is the dotted line). Figure 9 shows the displacement response of the deck to a force disturbance applied to the deck by the voice coil, for various values of the gain $g$, when only one control loop is in operation. Figure 9,

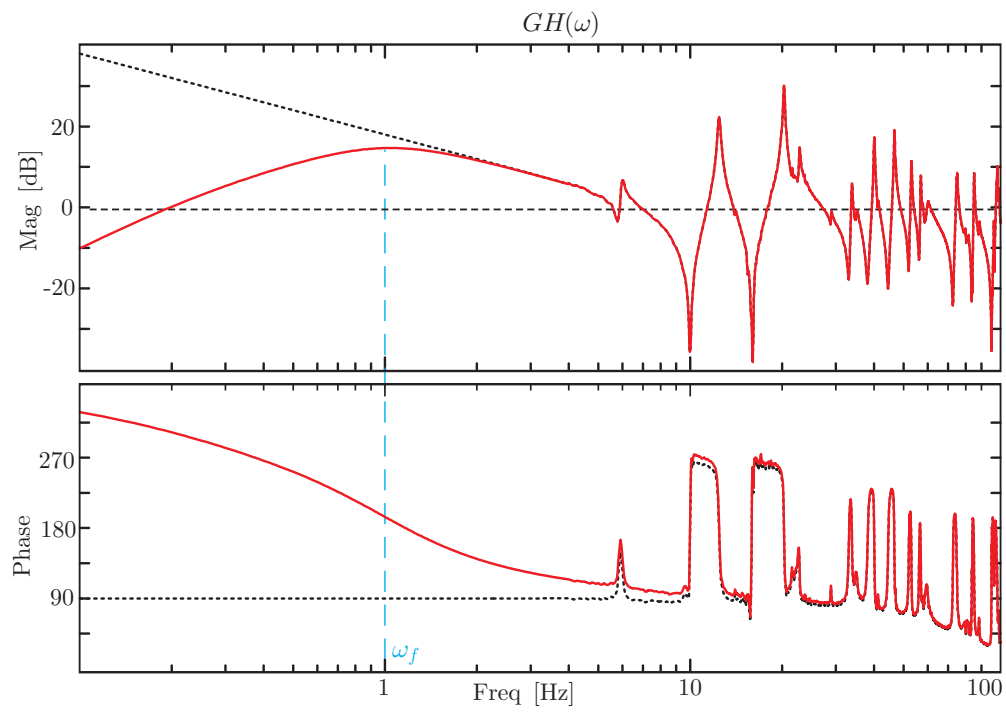

Figure 8. Loop gain $G H(\omega)$ of one control loop including the controller and the charge amplifier (IFF is the dotted line). 


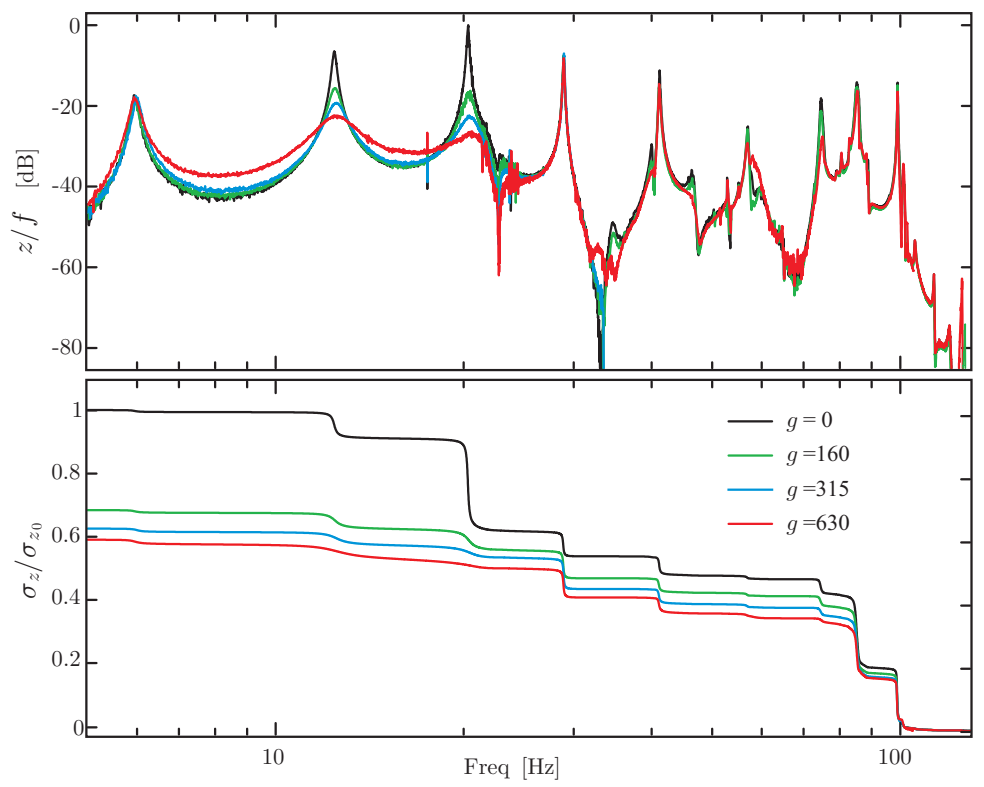

Figure 9. Response to disturbance $z / f$ with one loop of control, for various values of the gain $g$. Top: experimental FRF. Bottom: cumulative RMS $\sigma(\omega)$, normalized to its value when $g=0$.

top, shows the experimental frequency response function (FRF) $R(\omega)=z / f$ between the force $f$ applied to the deck by the voice coil and the deck displacement $z$ for various gains; Figure 9, bottom, shows the cumulative RMS defined as

$$
\sigma(\omega)=\left[\int_{\omega}^{\infty}|R(v)|^{2} d v\right]^{1 / 2}
$$

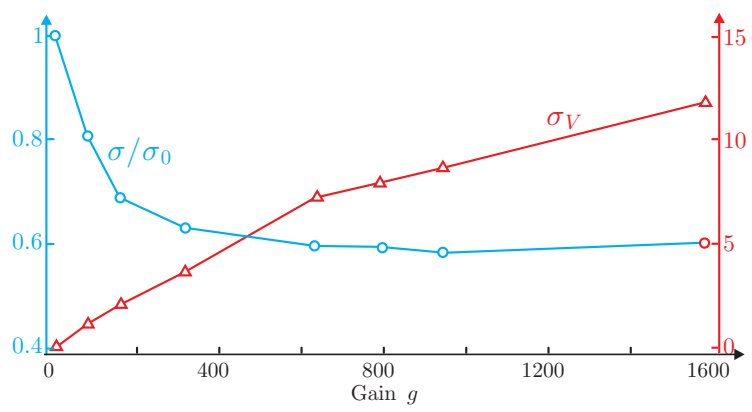

Figure 10. Response with one control loop. Evolution of the RMS value of the deck displacement $z$ (normalized to the uncontrolled response) and the actuator input $v$ as a function of the control gain. 




Figure 11. Response with one control loop. Root-locus reconstruction for various values of the gain: $g=0,160,300,650,800$, 950,1200 and comparison with the root locus of (1). Only the upper half of the root locus is shown.

(this form assumes a white noise input $f$ ). The steps in the diagram indicate how much each mode contributes to the RMS response. Increasing values of the gain lead to increasing values of the control force. Figure 10 shows the influence of the control gain on the overall RMS value of the response and the RMS value of the control input, measured here by the voltage $v$ applied to the piezoelectric actuator. One sees that, for small gains, the response reduces quickly, but for values larger than $g=300$, no further reduction is achieved in the response while the control input increases steadily; this diagram allows us to make a tradeoff between performance and control cost. Figure 11 shows the root-locus reconstruction for various values of the gain, $g=0,160,300,650,800,950,1200$, and the comparison with the root-locus prediction of (1); the part of the locus in the vicinity of the real axis corresponds to the charge amplifier.

\section{Decentralized control with four loops}

Next, a decentralized active damping has been implemented with four independent loops using the same gain. Figure 12 shows the same information as Figure 9, with four channels of control, and Figure 13 shows the root-locus reconstruction of the closed-loop poles for various values of the gain: $g=50,70,100,210,300,500$, 600,700 . Observe in Figure 12 that spillover ${ }^{3}$ is totally absent.

${ }^{3}$ Spillover is the phenomenon by which the active damping of the low-frequency modes is achieved at the expense of decreasing the damping, and possibly destabilizing the high-frequency modes, outside the bandwidth of the controller. 




Figure 12. Decentralized control with four independent control loops. Response to disturbance $z / f$, for various values of the gain $g$. Top: FRF. Bottom: cumulative RMS $\sigma(\omega)$, normalized to its value when $g=0$.

Finally, regarding the quality of the model and the ability of the fairly simple linear bridge model to capture properly the closed-loop response, Figure 14 compares the FRF $z / f$ obtained experimentally with those obtained with the numerical



Figure 13. Decentralized control with four independent loops. Root locus reconstruction for various values of the gain: $g=50$, $70,100,210,300,500,600,700$. 

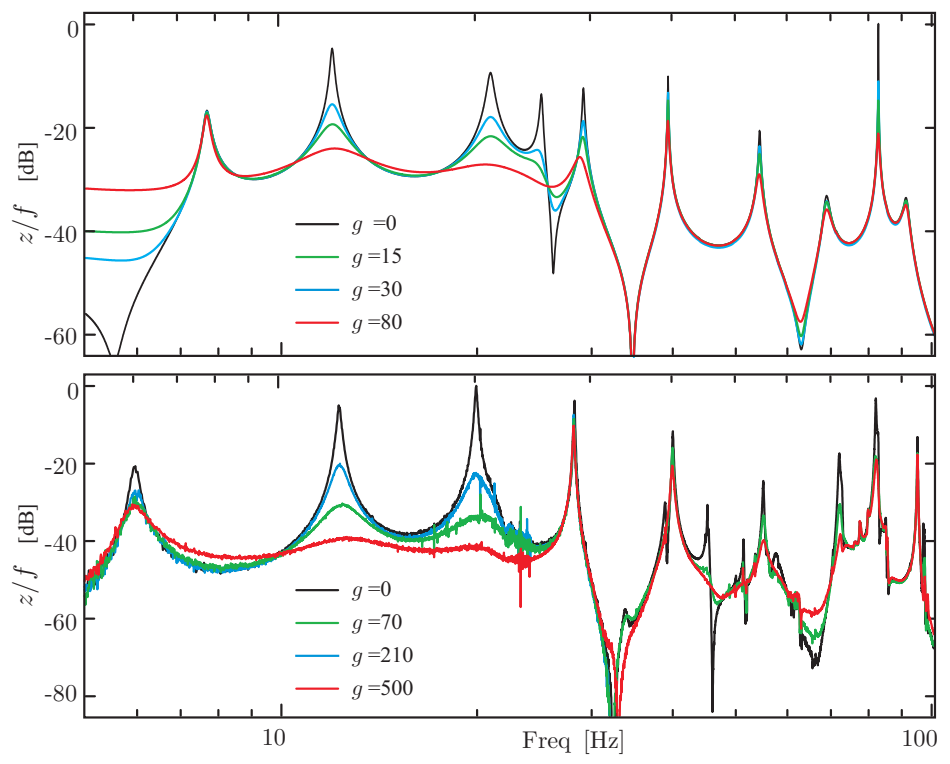

Figure 14. Decentralized control with four independent control loops. Response to disturbance $z / f$, for various values of the gain $g$. Comparison between numerical predictions and experimental results (only the relative values of $g$ matter). Top: model. Bottom: experiment.

model (the absolute values of the gain are irrelevant here because the experimental loop gain includes many items such as charge amplifier gain, current amplifier gain, etc., which do not appear in the numerical model).

\section{Summary and conclusion}

This paper explores the feasibility of active damping of suspension bridges with the addition of stay cables controlled with active tendons. An active tendon consists of a displacement actuator collocated with a force sensor monitoring the tension in the cable. The active tendons are controlled with decentralized integral force feedback (IFF). In the first part of the paper, the potential of the control strategy has been evaluated on a numerical model of an existing footbridge; several configurations have been investigated where the active cables connect the pylon to the deck or the deck to the catenary. The analysis confirmed that it is possible to provide a set of targeted modes with a considerable amount of damping, reaching $\xi=15 \%$. In the second part of the paper, the control strategy has been demonstrated experimentally on a laboratory mock-up equipped with four control stay cables. The experimental results confirm the excellent performance and robustness of the control system and 
the very good agreement with the predictions. The linear bridge model is sufficient to capture properly the closed-loop response. The next logical step towards the application of the idea to large suspension bridges should be a full scale experiment on a footbridge.

\section{Acknowledgements}

The authors wish to thank Professor Carmelo Gentile from the Civil Engineering Department of the Politecnico di Milano for providing the data of the Seriate footbridge and Professor Mihaita Horodinca from the Technical University "Gheorghe Asachi” of Iași, Romania, for his help in the construction of the bridge mock-up.

\section{Appendix A: Decentralized active damping of a cable-structure}

Consider the cable-structure system similar to that of Figure 15, where a passive structure is connected to a set of active cables operated with active tendons. In the example shown, the passive structure consists of a vertical truss structure and there are three active cables and three active tendons. Each active tendon consists of a displacement actuator (e.g., piezoelectric) colinear with a force sensor. $T_{i}$ is the tension in the active cable $i$, measured by the sensor integrated in the active tendon, $\delta_{i}$ is the free extension of the actuator, the variable used to control the system, and $k_{i}$ is the axial stiffness of the cable and the active tendon, jointly. We assume that the dynamics of the active cables can be neglected and that their interaction with the structure is restricted to the tension $T_{i}$. Assuming a classical finite-element


Figure 15. Left: cable-structure system with active tendons. Center: active tendon. Right: passive structure. 
formulation, the equation governing the dynamic response of the system is ${ }^{4}$

$$
M \ddot{x}+K x=-B T+f,
$$

where $x$ is the vector of global coordinates of the finite-element model, $M$ and $K$ are the mass and stiffness matrices of the passive structure, respectively (including a linear model of the passive cables, if any, but excluding the active cables). The right-hand side represents the external forces applied to the system; $f$ is the vector of external disturbances such as gravity and wind loads (expressed in global coordinates), $T=\left(T_{1}, \ldots, T_{i}, \ldots\right)^{T}$ is the vector of tension in the active cables, and $B$ is the influence matrix of the cable forces, projecting the cable forces in the global coordinate system (the columns of $B$ contain the direction cosines of the various active cables). $B$ depends on the topology of the active cable network.

If we neglect the cable dynamics, the active cables behave like (massless) bars. If $\delta=\left(\delta_{1}, \ldots, \delta_{i}, \ldots\right)^{T}$ is the vector of (free) active displacements of the active tendons acting along the cables, the tension in the cables is given by

$$
T=K_{c}\left(B^{T} x-\delta\right),
$$

where $K_{c}=\operatorname{diag}\left(k_{i}\right)$ is the stiffness matrix of the cables and $B^{T} x$ is the relative displacements of the end points of the cables projected along the chord lines. This equation expresses that the tension in the cable is associated with the elastic extension of the cable. Combining (A-1) and (A-2), we get

$$
M \ddot{x}+\left(K+B K_{c} B^{T}\right) x=B K_{c} \delta+f .
$$

This equation indicates that $K+B K_{c} B^{T}$ is the stiffness matrix of the structure including all the guy cables (passive and active). Next, we assume that all the active cables are controlled according to the decentralized force feedback law:

$$
\delta=g h(s) K_{c}^{-1} T,
$$

where $g h(s)$ is the scalar control law applied to all control channels ${ }^{5}$ (note that $K_{c}^{-1} T$ represents the elastic extension of the active cables). Combining (A-2) through (A-4), the closed-loop equation is

$$
\left[M s^{2}+K+\frac{1}{1+g h(s)} B K_{c} B^{T}\right] x=f .
$$

It is readily observed that the open-loop poles, solutions of the characteristic equation for $g=0$, satisfy

$$
\left[M s^{2}+K+B K_{c} B^{T}\right] x=0
$$

${ }^{4}$ We momentarily neglect the structural damping to make the equations formally simpler.

${ }^{5}$ Here $s$ is the Laplace variable. 
(the solutions are the eigenvalues of the structure with all cables) while the transmission zeros, solutions of (A-5) for $g \rightarrow \infty$, satisfy

$$
\left[M s^{2}+K\right] x=0,
$$

which is the eigenvalue problem for the open-loop structure where the active cables have been removed (they can be computed very easily).

Control law. If an integral force feedback (IFF) controller is used, $h(s)=s^{-1}$ and the closed-loop equation becomes

$$
\left[M s^{2}+K+\frac{s}{s+g} B K_{c} B^{T}\right] x=f,
$$

which indicates that the closed-loop static stiffness matrix is

$$
\lim _{s \rightarrow 0}\left[M s^{2}+K+\frac{s}{s+g} B K_{c} B^{T}\right]=K .
$$

This means that the active cables do not contribute to the static stiffness, and this may be problematic in applications. However, the static stiffness can be recovered if a high-pass filter is inserted in the control loop. One way to achieve this is to change the control law into ${ }^{6}$

$$
g h(s)=\frac{g s}{(s+\beta)^{2}},
$$

where $\beta$ is small and positive (the influence of $\beta$ will be discussed later); the closedloop equation becomes

$$
\left[M s^{2}+K+\frac{(s+\beta)^{2}}{g s+(s+\beta)^{2}} B K_{c} B^{T}\right] x=f,
$$

and the closed-loop static stiffness matrix becomes

$$
\lim _{s \rightarrow 0}\left[M s^{2}+K+\frac{(s+\beta)^{2}}{g s+(s+\beta)^{2}} B K_{c} B^{T}\right]=K+B K_{c} B^{T},
$$

which indicates that the active cables have a full contribution to the static stiffness.

Modal behavior. Next, let us project the characteristic equation on the normal modes of the structure with all the cables, $x=\Phi z$, which are normalized according to $\Phi^{T} M \Phi=1$. According to the orthogonality condition of the normal modes [Gawronski 2004],

$$
\Phi^{T}\left(K+B K_{c} B^{T}\right) \Phi=\Omega^{2}=\operatorname{diag}\left(\Omega_{i}^{2}\right),
$$

\footnotetext{
${ }^{6}$ We will refer to this as the beta controller in what follows.
} 
where $\Omega_{i}$ are the natural frequencies of the complete structure. In order to derive a simple and powerful result about the way each mode evolves with $g$, let us assume that the mode shapes are little changed by the active cables so that we can write

$$
\Phi^{T} K \Phi \approx \omega^{2}=\operatorname{diag}\left(\omega_{i}^{2}\right),
$$

where $\omega_{i}$ are the natural frequencies of the structure where the active cables have been removed. It follows that the fraction of modal strain energy contained in the active cables is given by

$$
v_{i}=\frac{\phi_{i}^{T} B K_{c} B^{T} \phi_{i}}{\phi_{i}^{T}\left(K+B K_{c} B^{T}\right) \phi_{i}}=\frac{\Omega_{i}^{2}-\omega_{i}^{2}}{\Omega_{i}^{2}} .
$$

Considering the IFF controller, the closed-loop characteristic equation (A-8) can be projected into modal coordinates, leading to

or

$$
\left(s^{2}+\Omega_{i}^{2}\right)-\frac{g}{g+s}\left(\Omega_{i}^{2}-\omega_{i}^{2}\right)=0
$$

$$
1+g \frac{s^{2}+\omega_{i}^{2}}{s\left(s^{2}+\Omega_{i}^{2}\right)}=0 .
$$

This result indicates that the closed-loop poles can be predicted by performing two modal analyses (Figure 16), one with all the cables, leading to the open-loop poles $\pm j \Omega_{i}$, and one with only the passive cables, leading to the open-loop zeros $\pm j \omega_{i}$, and drawing the independent root loci (A-16). The maximum modal damping is given by

$$
\xi_{i}^{\max }=\frac{\Omega_{i}-\omega_{i}}{2 \omega_{i}},
$$

and it is achieved for $g=\Omega_{i} \sqrt{\Omega_{i} / \omega_{i}}$; a formal proof of this result is given in Appendix B. This equation relates directly the maximum achievable modal damping with the spacing between the pole $\Omega_{i}$ and the zero $\omega_{i}$, which is essentially controlled by the fraction of modal strain energy in the active cables, as expressed by $(\mathrm{A}-15)$.

The foregoing results are very easy to use in design. Although they are based on several assumptions (namely that the dynamics of the active cables can be neglected, that the passive cables behave linearly, and that the mode shapes are unchanged), they are in good agreement with experiments [Preumont and Achkire 1997; Preumont et al. 2000].

If, instead of the IFF controller, the beta controller is used, the closed-loop characteristic equation projected into modal coordinates reads

$$
\left(s^{2}+\Omega_{i}^{2}\right)-\frac{g s}{g s+(s+\beta)^{2}}\left(\Omega_{i}^{2}-\omega_{i}^{2}\right)=0
$$




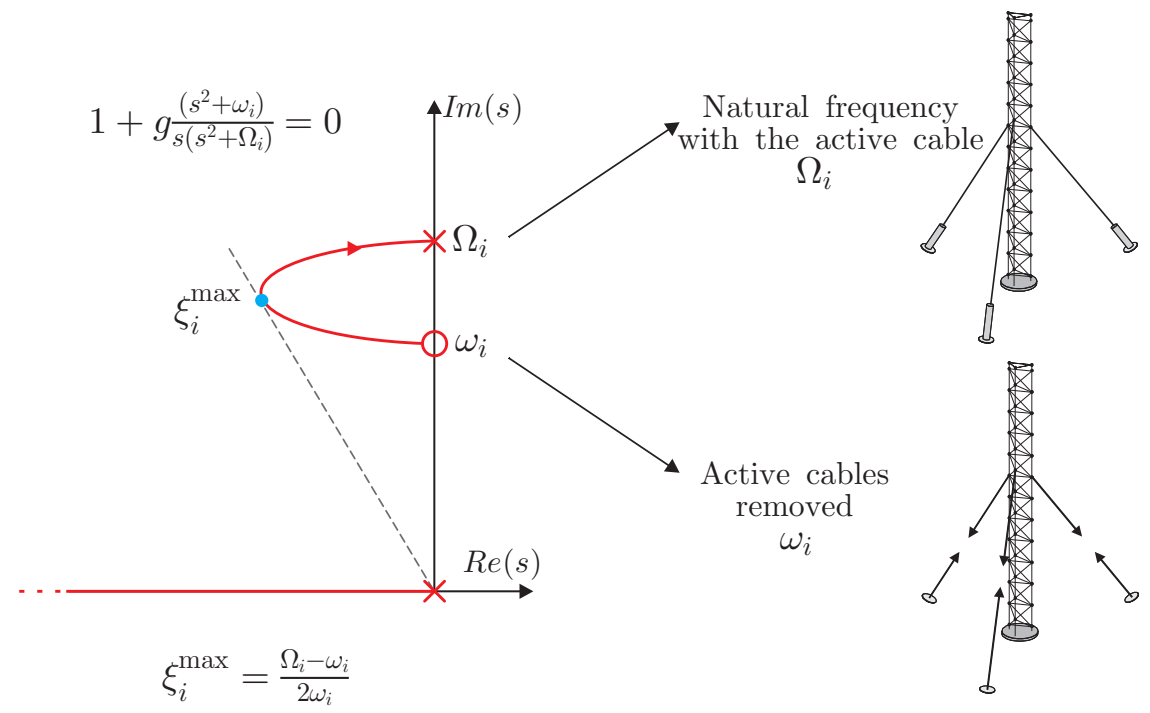

Figure 16. Root locus of the closed-loop poles with an IFF controller. The system is unconditionally stable.

or

$$
1+g \frac{s\left(s^{2}+\omega_{i}^{2}\right)}{(s+\beta)^{2}\left(s^{2}+\Omega_{i}^{2}\right)}=0 .
$$

Thus, as compared to the IFF controller, the pole at the origin has been replaced by a zero at the origin and a pair of poles at $-\beta$ on the real axis. The effect of this change on the root locus is shown in Figure 17. When $\beta=0$, there is a pole-zero cancellation and the control is reduced to the IFF. As $\beta$ increases, the root locus has
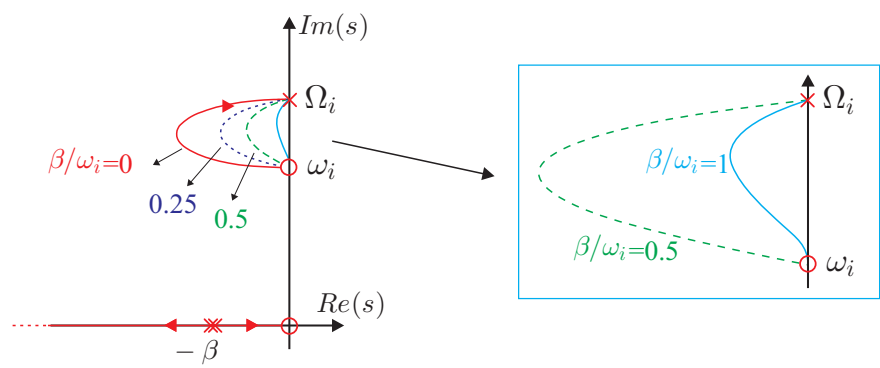

Figure 17. Root locus of the closed-loop poles with the beta controller $g s /(s+\beta)^{2}$, for various values of the ratio $\beta / \omega_{i}$. The IFF controller corresponds to $\beta=0$. The locus is always stable for $\beta<\omega_{i}$; for $\beta=\omega_{i}$, it is tangent to the imaginary axis at the zero $\pm j \omega_{i}$. 
two branches on the real axis, starting from $s=-\beta$ in opposite directions; one of the closed-loop poles remains trapped between 0 and $-\beta$. The loops still go from $\pm j \Omega_{i}$ to $\pm j \omega_{i}$, but they tend to be smaller, leading to less active damping; this is the price to pay for recovering the static stiffness of the active cables. Analyzing the root locus in detail, one can show that the system is unconditionally stable (for all modes) provided that $\beta<\omega_{1}$.

\section{Appendix B: Proof of (A-17)}

The characteristic equation corresponding to (A-16) reads

$$
s^{3}+g s^{2}+\Omega_{i}^{2} s+g \omega_{i}^{2}=0 .
$$

The root locus (locus of the solutions of the characteristic equation when $g$ varies from 0 to $\infty$; see Figure 16) has one branch on the negative real axis (say at $-a$ ) and two branches corresponding to a complex conjugate pair at $-\xi \omega \pm j \omega \sqrt{1-\xi^{2}}$. This leads to the characteristic equation

$$
(s+a)\left(s^{2}+2 \xi \omega s+\omega^{2}\right)=0,
$$

where $a, \xi$, and $\omega$ depend on the gain $g$. Observe that the frequency $\omega$ decreases monotonously from $\Omega_{i}$ to $\omega_{i}$. Matching the coefficients of the two foregoing equations, one gets the three identities

$$
a \omega^{2}=g \omega_{i}^{2}, \quad 2 a \xi \omega+\omega^{2}=\Omega_{i}^{2}, \quad a+2 \xi \omega=g .
$$

We seek the maximum value of $\xi$ and the corresponding value of the gain $g$. From the first equality, $a=g \omega_{i}^{2} / \omega^{2}$; substituting in the other two equalities,

$$
2 g \omega_{i}^{2} \xi / \omega+\omega^{2}=\Omega_{i}^{2}, \quad g \omega_{i}^{2} / \omega^{2}+2 \xi \omega=g .
$$

From the second of these equalities, one finds

$$
\xi=\frac{g}{2 \omega}\left(1-\frac{\omega_{i}^{2}}{\omega^{2}}\right),
$$

and substituting into the first one,

$$
g^{2}=\left(\frac{\Omega_{i}^{2}-\omega^{2}}{\omega^{2}-\omega_{i}^{2}}\right) \frac{\omega^{4}}{\omega_{i}^{2}} .
$$

Back-substituting into (B-3), one finds the relationship between $\xi$ and $\omega$ along the root locus:

$$
\xi=\frac{\left[\left(\Omega_{i}^{2}-\omega^{2}\right)\left(\omega^{2}-\omega_{i}^{2}\right)\right]^{1 / 2}}{2 \omega_{i} \omega} .
$$


This expression may be regarded as $\xi(\omega)$ (recall that $\omega$ is monotonously decreasing in $g$ ). Solving the equation $d \xi / d \omega=0$, one easily finds

$$
\omega=\left(\Omega_{i} \omega_{i}\right)^{1 / 2}
$$

and, substituting in (B-4),

$$
g=\Omega_{i}\left(\Omega_{i} / \omega_{i}\right)^{1 / 2},
$$

and from $(\mathrm{B}-3)$, the maximum damping ratio is

$$
\xi=\frac{\Omega_{i}-\omega_{i}}{2 \omega_{i}}
$$

which is the desired equation. Additionally, one finds $a=\left(\Omega_{i} \omega_{i}\right)^{1 / 2}$.

\section{References}

[Achkire and Preumont 1996] Y. Achkire and A. Preumont, "Active tendon control of cable-stayed bridges”, Earthq. Eng. Struct. D. 25:6 (1996), 585-597.

[Achkire and Preumont 1998] Y. Achkire and A. Preumont, "Optical measurement of cable and string vibration", Shock Vib. 5:3 (1998), 171-179.

[Achkire et al. 1998] Y. Achkire, F. Bossens, and A. Preumont, "Active damping and flutter control of cable-stayed bridges", J. Wind. Eng. Ind. Aerod. 74-76 (1998), 913-921.

[Auperin and Dumoulin 2001] M. Auperin and C. Dumoulin, "Structural control: point of view of a civil engineering company in the field of cable-supported structures", pp. 49-57 in Structural control for civil and infrastructure engineering (Paris, 2000), edited by F. Casciati and G. Magonette, World Scientific, Singapore, 2001.

[Bossens and Preumont 2001] F. Bossens and A. Preumont, "Active tendon control of cable-stayed bridges: a large-scale demonstration”, Earthq. Eng. Struct. D. 30:7 (2001), 961-979.

[Caetano et al. 2010] E. Caetano, Á. Cunha, C. Moutinho, and F. Magalhães, "Studies for controlling human-induced vibration of the Pedro e Inês footbridge, Portugal, II: Implementation of tuned mass dampers", Eng. Struct. 32:4 (2010), 1082-1091.

[Cannon and Rosenthal 1984] R. H. Cannon, Jr. and D. E. Rosenthal, "Experiments in control of flexible structures with noncolocated sensors and actuators", J. Guid. Control Dynam. 7:5 (1984), 546-553.

[Pinto da Costa et al. 1996] A. Pinto da Costa, J. A. C. Martins, F. Branco, and J. L. Lilien, "Oscillations of bridge stay cables induced by periodic motions of deck and/or towers", J. Eng. Mech. 122:7 (1996), 613-622.

[Fujino and Susumpow 1994] Y. Fujino and T. Susumpow, "An experimental study on active control of in-plane cable vibration by axial support motion”, Earthq. Eng. Struct. D. 23:12 (1994), 12831297.

[Fujino et al. 1993] Y. Fujino, P. Warnitchai, and B. M. Pacheco, "Active stiffness control of cable vibration", J. Appl. Mech. 60:4 (1993), 948-953.

[Gawronski 2004] W. K. Gawronski, Advanced structural dynamics and active control of structures, Springer, New York, 2004.

[Lilien and Pinto da Costa 1994] J. L. Lilien and A. Pinto da Costa, "Vibration amplitudes caused by parametric excitation of cable stayed structures", J. Sound. Vib. 174:1 (1994), 69-90. 
[Nayfeh and Mook 1979] A. H. Nayfeh and D. T. Mook, Nonlinear oscillations, Wiley, New York, 1979.

[Pacheco et al. 1993] B. Pacheco, Y. Fujino, and A. Sulekh, "Estimation curve for modal damping in stay cables with viscous damper”, J. Struct. Eng. 119:6 (1993), 1961-1979.

[Preumont 2011] A. Preumont, Vibration control of active structures: an introduction, 3rd ed., Solid Mechanics and its Applications 179, Springer, Berlin, 2011.

[Preumont and Achkire 1997] A. Preumont and Y. Achkire, "Active damping of structures with guy cables", J. Guid. Control Dynam. 20:2 (1997), 320-326.

[Preumont and Bossens 2000] A. Preumont and F. Bossens, "Active tendon control of vibration of truss structures: theory and experiments”, J. Intel. Mat. Syst. Str. 11:2 (2000), 91-99.

[Preumont et al. 1992] A. Preumont, J.-P. Dufour, and C. Malékian, "Active damping by a local force feedback with piezoelectric actuators", J. Guid. Control Dynam. 15:2 (1992), 390-395.

[Preumont et al. 2000] A. Preumont, Y. Achkire, and F. Bossens, "Active tendon control of large trusses", AIAA J. 38:3 (2000), 493-498.

[Sangiovanni and Voltan 2015] A. Sangiovanni and M. Voltan, Active tendon control of suspension bridges, master's thesis, Politecnico di Milano, 2015, Available at http://hdl.handle.net/10589/ 107971.

[Tubino and Piccardo 2015] F. Tubino and G. Piccardo, "Tuned Mass Damper optimization for the mitigation of human-induced vibrations of pedestrian bridges", Meccanica 50:3 (2015), 809-824.

[Van Nimmen et al. 2014] K. Van Nimmen, G. Lombaert, G. De Roeck, and P. Van den Broeck, "Vibration serviceability of footbridges: evaluation of the current codes of practice", Eng. Struct. 59 (2014), 448-461.

[Warnitchai et al. 1993] P. Warnitchai, Y. Fujino, B. M. Pacheco, and R. Agret, "An experimental study on active tendon control of cable-stayed bridges", Earthq. Eng. Struct. D. 22:2 (1993), 93111.

[Yang and Giannopoulos 1979a] J.-N. Yang and F. Giannopoulos, "Active control and stability of cable-stayed bridge”, J. Eng. Mech. 105:4 (1979), 677-694.

[Yang and Giannopoulos 1979b] J.-N. Yang and F. Giannopoulos, "Active control of two-cablestayed bridge", J. Eng. Mech. 105:5 (1979), 795-810.

Received 16 Jun 2015. Revised 30 Sep 2015. Accepted 8 Nov 2015.

ANDRÉ PREUMONT: apreumon@ulb.ac.be

Active Structures Laboratory, Université Libre de Bruxelles, 1000 Brussels, Belgium

MATTEO Voltan: matteo.voltan@mail.polimi.it

Department of Mechanical Engineering, Politecnico di Milano, I-20133 Milan, Italy

ANDREA SANGIOVANNI: andrea.sangiovanni@mail.polimi.it

Department of Mechanical Engineering, Politecnico di Milano, I-20133 Milan, Italy

RENAUD BASTAITS: rbastait@ulb.ac.be

Active Structures Laboratory, Université Libre de Bruxelles, 1000 Brussels, Belgium

BILAL MOKRANI: bilal.mokrani@ulb.ac.be

Active Structures Laboratory, Université Libre de Bruxelles, 1000 Brussels, Belgium

DAVID AlaLuf: dalaluf@ulb.ac.be

Active Structures Laboratory, Université Libre de Bruxelles, 1000 Brussels, Belgium 
EDITORIAL BOARD

ANTONIO CARCATERRA

ERIC A. CARLEN

FRANCESCO DELL'ISOLA

RAFFAELE ESPOSITO

ALBERT FANNJIANG

Gilles A. FranCFORT

Pierangelo MARCATI

JEAN-JACQUES MARIGO

PETER A. MARKOWICH

MARTIN OSTOJA-STARZEWSKI

PIERRE SEPPECHER

DAVID J. STEIGMANN

PAUl STEINMANN

PierRe M. SuQueT

MANAGING EDITORS

MICOL AMAR

CORRADO LATTANZIO

ANGELA MADEO

MARTIN OSTOJA-STARZEWSKI

ADVISORY BOARD

ADNAN AKAY

Holm AltenBaCH

MICOL AMAR

HARM ASKES

TEODOR ATANACKOVIĆ

VICTOR BERDICHEVSKY

GUY BOUCHITTÉ

ANDREA BRAIDES

ROBERTO CAMASSA

MAURO CARFORE

ERIC DARVE

FELIX DARVE

ANNA DE MASI

GianPiEtro DEL Piero

EMMANUELE Di BENEDETTO

BERNOLD FIEDLER

IRENE M. GAMBA

DAVID Y. GAO

SERGEY GAVRILYUK

TIMOTHY J. HEALEY

DOMINIQUE JEULIN

ROGER E. KHAYAT

CORRADO LATTANZIO

ROBERT P. LIPTON

ANGELO LUONGO

ANGELA MADEO

JUAN J. MANFREDI

CARLO MARCHIORO

GÉRARD A. MAUGIN

ROBERTO NATALINI PATRIZIO NEFF

ANDREY PIATNITSKI

ERRICO PRESUTTI

MARIO PULVIRENTI

LUCIO RUSSO

Miguel A. F. SANJUAN

PATRICK SElVADURAI

ALEXANDER P. SEYRANIAN

MIROSLAV ŠILHAVÝ

GUIDO SWEERS

ANTOINETTE TORDESILLAS

LEV TRUSKINOVSKY

JUAN J. L. VELÁZQUEZ VINCENZO VESPRI ANGELO VULPIANI msp.org/memocs

Università di Roma "La Sapienza", Italia

Rutgers University, USA

(CO-CHAIR) Università di Roma "La Sapienza", Italia

(TREASURER) Università dell'Aquila, Italia

University of California at Davis, USA

(CO-CHAIR) Université Paris-Nord, France

Università dell'Aquila, Italy

École Polytechnique, France

DAMTP Cambridge, UK, and University of Vienna, Austria

(CHAIR MANAGING EDITOR) Univ. of Illinois at Urbana-Champaign, USA

Université du Sud Toulon-Var, France

University of California at Berkeley, USA

Universität Erlangen-Nürnberg, Germany

LMA CNRS Marseille, France

Università di Roma "La Sapienza", Italia

Università dell'Aquila, Italy

Université de Lyon-INSA (Institut National des Sciences Appliquées), France

(CHAIR MANAGING EDITOR) Univ. of Illinois at Urbana-Champaign, USA

Carnegie Mellon University, USA, and Bilkent University, Turkey

Otto-von-Guericke-Universität Magdeburg, Germany

Università di Roma "La Sapienza", Italia

University of Sheffield, UK

University of Novi Sad, Serbia

Wayne State University, USA

Université du Sud Toulon-Var, France

Università di Roma Tor Vergata, Italia

University of North Carolina at Chapel Hill, USA

Università di Pavia, Italia

Stanford University, USA

Institut Polytechnique de Grenoble, France

Università dell'Aquila, Italia

Università di Ferrara and International Research Center MEMOCS, Italia

Vanderbilt University, USA

Freie Universität Berlin, Germany

University of Texas at Austin, USA

Federation University and Australian National University, Australia

Université Aix-Marseille, France

Cornell University, USA

École des Mines, France

University of Western Ontario, Canada

Università dell' Aquila, Italy

Louisiana State University, USA

Università dell'Aquila, Italia

Université de Lyon-INSA (Institut National des Sciences Appliquées), France University of Pittsburgh, USA

Università di Roma "La Sapienza”, Italia

Université Paris VI, France

Istituto per le Applicazioni del Calcolo "M. Picone", Italy

Universität Duisburg-Essen, Germany

Narvik University College, Norway, Russia

Università di Roma Tor Vergata, Italy

Università di Roma "La Sapienza”, Italia

Università di Roma “Tor Vergata”, Italia

Universidad Rey Juan Carlos, Madrid, Spain

McGill University, Canada

Moscow State Lomonosov University, Russia

Academy of Sciences of the Czech Republic

Universität zu Köln, Germany

University of Melbourne, Australia

École Polytechnique, France

Bonn University, Germany

Università di Firenze, Italia

Università di Roma La Sapienza, Italia

MEMOCS (ISSN 2325-3444 electronic, 2326-7186 printed) is a journal of the International Research Center for the Mathematics and Mechanics of Complex Systems at the Università dell'Aquila, Italy.

Cover image: "Tangle” by $\odot$ John Horigan; produced using the Context Free program (contextfreeart.org).

PUBLISHED BY

7 mathematical sciences publishers

nonprofit scientific publishing

http://msp.org/

(C) 2015 Mathematical Sciences Publishers 
Mathematics and Mechanics of Complex Systems vol. 3 no. 4

An analysis of the latitudinal data of Eratosthenes and Hipparchus

\section{Christian Marx}

Spatial and material stress tensors in continuum mechanics 341 of growing solid bodies

Jean-François Ganghoffer

A crack with surface elasticity in finite plane elastostatics 365 $\mathrm{Xu}$ Wang and Peter Schiavone

An investigation of the active damping of suspension bridges

André Preumont, Matteo Voltan, Andrea Sangiovanni, Renaud Bastaits, Bilal Mokrani and David Alaluf

MEMOCS is a journal of the International Research Center for the Mathematics and Mechanics of Complex Systems at the Università dell' Aquila, Italy.



